Europe's Journal of Psychology, 7(1), pp. 40-61

www.ejop.org

\title{
Talking about traumatic events: A cross-cultural investigation
}

\author{
Simone Freitag \\ Anna Grimm \\ Silke Schmidt
}

Department Health \& Prevention, Institute of Psychology,

Ernst-Moritz-Arndt University, Greifswald

\begin{abstract}
Individuals are facing traumatic situations like natural crises (like floods, earthquakes) and man-made disasters (terroristic attacks) incrementally. Traumatic events are related to psychological consequences for survivors (depression, posttraumatic stress disorder). The experience of a traumatic event can be disclosed through narratives, which can be linguistically analyzed with the Linguistic Inquiry and Word Count (LIWC). In this study, cultural and temporal differences in narratives about different traumatic events in seven European countries are investigated. 132 survivors, who experienced a traumatic situation, reported their experiences in focus groups and interviews. The transcripts of narratives were analyzed with the LIWC2007 (Pennebaker, Chung, Ireland, Gonzales \& Booth, 2007). Regarding the LIWC categories affective and cognitive processes, event characteristics as well as cultural and temporal differences were explored. Results show that traumatic situations are reported with a greater amount of negative emotion words. Cultural differences regarding the LIWC categories are found between the seven European countries. A temporal factor, considering days elapsed between an event and narrative, was investigated. Temporal differences in cognitive word use, but not for affective contents, were recognized. This study was able to show tendencies of cultural diversity in the expression of traumatic events in survivors of seven European countries as well as to explore a temporal factor, which is related to a retrospective way of narration.
\end{abstract}

Keywords: traumatic event, crisis, LIWC, affective, emotion, cognition, word use.

Societies are threatened by events like hurricanes, floods, fires and nowadays by terroristic activities like the World Trade Center (WTC) attacks on September, $11^{\text {th }}$ 
2001 or the London Tube bombings in 2005. In fact, societies are affected by a lot of threats, which can cause severe impact on population in terms of increased prevalence of Posttraumatic Stress Disorders (PTSD; (Galea, et al., 2002; Kessler, Sonnega, Bromet, Hughes, \& Nelson, 1995; Miguel-Tobal, et al., 2006; Schlenger, et al., 2002). Most threats can be categorized as natural disasters versus human-made disasters (Marsella, Johnson, Watson, \& Gryczynski, 2008, p. 7). Natural disasters are characterized as event over which humans have no control like flood, fire and earthquake. Therefore, only preventive strategies can be employed (Marsella, et al., 2008). The experience of a flood followed by the loss of property is related to increased psychological health issues (Carroll, Morbey, Balogh, \& Araoz, 2009). Experiencing an earthquake and being rescued is associated with increased distress and high prevalence of PTSD even four years after the events' occurrence (Livanou, et al., 2005). Surviving a residential fire is also accompanied by heightened distress (Keane, Pickett, Jepson, McCorkle, \& Lowery, 1994). Human- or man-made disasters are directly linked with human behavior in terms of accidents, violence and human failures like terrorist attacks, war or rape (Marsella, et al., 2008). Terrorist attacks like the WTC attack on September $11^{\text {th }} 2001$ or the Madrid train bombings in March 2004 are accompanied by increased prevalence for major depression and PTSD (Galea, et al., 2002; Miguel-Tobal, et al., 2006; Schlenger, et al., 2002).

Linguistic Analysis

Research has shown that such traumatic events have long-term effects on the individual's health. Hence, little is known about the individuals' cognition and emotions during and after a traumatic event. Useful sources to investigate individuals' perception of traumatic events are personal narratives about it (Smyth, Hockemeyer, \& Tulloch, 2008; Smyth, True, \& Souto, 2001). Therefore, the specific choice of words can be an indicator of the internal processes of the individual that experienced the event. The emotional state of a writer can be reflected in his/her words; anger is expressed by an increased use of negative emotion words whereas joy is expressed through positive emotion words (Gill, French, Gergle, \& Oberlander, 2008). Several studies have demonstrated that writing about a traumatic event is accompanied by an increased use of words reflecting emotions and cognition (Cohn, Mehl, \& Pennebaker, 2004; Gortner \& Pennebaker, 2003; Pennebaker \& Francis, 1996).

Written narratives can be analyzed with the computerized quantitative text analysis software, the Linguistic Inquiry and Word Count (latest version LIWC2007) developed by Pennebaker, Chung, Ireland, Gonzales \& Booth (2007). The software counts words of texts by default word categories. LIWC2007 contains about 80 categories like the 
file name, general descriptor categories (total word count, words per sentence), linguistic dimensions (pronouns, articles, auxiliary verbs) and amongst others word categories tapping psychological constructs (affect, cognition, biological processes) (further categories in LIWC 2007 Manual, Pennebaker et al., 2007). Exemplified in table 1 are the categories for affect and cognition words including subcategories, abbreviations and example words. A sentence containing the word "nice" would increase the subcategory "positive affect" as well as the superior category "affective processes" by percentage.

Table 1: LIWC2007 content categories of affective and cognitive processes, with subcategories, abbreviation and examples extracted from (Pennebaker, Chung, et al., 2007, p. 5)

\begin{tabular}{lll}
\hline Category & Abbreviation & Examples \\
\hline Affective processes & affect & Happy, cried, abandon \\
Positive emotion & posemo & Love, nice, sweet \\
Negative emotion & negemo & Hurt, ugly, nasty \\
Anxiety & anx & Worried, fearful, nervous \\
Anger & anger & Hate, kill, annoyed \\
Sadness & sad & Crying, grief, sad \\
Cognitive processes & cogmech & cause, know, ought \\
Insight & insight & think, know, consider \\
Causation & cause & because, effect, hence \\
Discrepancy & discrep & should, would, could \\
Tentative & tentat & maybe, perhaps, guess \\
Certainty & certain & always, never \\
Inhibition & inhib & block, constrain, stop \\
Inclusive & incl & And, with, include \\
\hline
\end{tabular}

As demonstrated, a lot of studies and findings are available for the word categories affective and cognitive processes. LIWC analysis of students' essays about traumatic and neutral events revealed that writings about traumatic events contained more emotion related words than writings about neutral topics (Pennebaker \& Beall, 1986). The expression of cognition and emotions in a disclosure task was found to increase positive growth after a trauma over time (Ulrich \& Lutgendorf, 2002). An increased use of cognitive words was more associated with health improvement than emotion word use (Pennebaker, Mehl, \& Niederhoffer, 2003). LIWC is sensitive to identify overall emotional expression (.88). Satisfying reliabilities for positive (.80) and negative emotions (.78) were found (Bantum \& Owen, 2009). 
Linguistic Characteristics of Traumatic events

As demonstrated, the experience of traumatic events is associated with a heightened likelihood of psychological impairment like PTSD, depression and anxiety disorders. Personal experiences, which are told or written, are related to specific linguistic patterns (Groom \& Pennebaker, 2002). Whether certain types of events are linked with certain linguistic patterns has not yet been analyzed.

Are there hints of how narratives about traumatic events are linguistically characterized? Narratives of negative life events with an emotional impact to the individual were characterized by an increased number of words, a greater number of sentences and they contained more emotional words compared to events without emotional impact (Rullkoetter, et al., 2009). Writing about cultural or community-wide upheavals was related to an increased use of first person plural "we" (Chung \& Pennebaker, 2007). Interviews with female sexual assault victims revealed a higher amount of words related to death and dying, which was associated with a poor perception of physical health and lower well-being. A greater use of cognitive words was related to less anxiety after a treatment (AlvarezConrad, Zoellner, \& Foa, 2001). In this study different traumatic events are examined in terms of their linguistic characteristics, affective and cognitive word use.

Do cultural differences appear in the linguistic expression of traumatic events? Yeomans, Forman, Eshun, \& Gurung (2009) explored the cultural factors in handling traumatic stress. Individuals of different cultures vary in the extent to which they express distress; for example, Asians are more reluctant to express distress in public. Differences between North-American and East-Asian narratives were found for the use of pronouns referring to the self "I" or collective "we" (Chung \& Pennebaker, 2007). From a psycho-linguistic point of view, cultural differences between an US and a Spanish sample have been explored. Fernandez, Paez, \& Pennebaker (2009) revealed differences between Spanish and American texts reporting about terroristic attacks. Significant differences regarding the emotional and cognitive LIWC categories in both samples were found: the US text sample comprised less affective or emotional processes than the Spanish. In both samples more negative (sadness, depression) than positive emotions were expressed. Regarding cognitive processes, significant differences were found for the use of causation words which was higher in Spanish texts; words of discrepancy and certainty were higher in the US writings (Fernandez, et al., 2009). Less research has been done exploring cultural differences between European countries. This study aims to investigate whether certain type of events differ linguistically in seven different European countries. 
Does the time of disclosing a traumatic event has an impact on the way the event is narrated? Temporal influences might have an impact on the content of traumatic event reports, in terms of increased use of emotion and cognition related words shortly after an event compared to the decreased use after a greater temporal distance between event and narrative. The "social stage model of collective coping" considers a temporal factor for the need to talk about a traumatic event (Pennebaker \& Harber, 1993). It contains three stages of coping with collective traumatic events: The emergency phase is characterized by an increased need for people to talk about the event and to build a collective script of the event. The emergency phase is followed by the inhibition phase. In the inhibition phase the talking is reduced, but thoughts about the event remain. At last the adaptation phase contains a further decrease of conversations and thoughts about the event until both are finally suspended. Linguistic differences between disclosed and undisclosed experiences have been investigated. Pasupathi (2007) found that recently disclosed experiences were reported with a greater amount of past tense words and references to others. Talking about traumatic events after months or years has not been investigated yet. In this study a temporal factor is investigated, considering the days passed between the event and the interview about the event.

Present study

This study aims to explore the use of emotional and cognitive words in retrospective reports of survivors who experienced the following traumatic events: residential fire, flood, earthquake, bus accident, collapse of a building, terrorist attack and fire in a public building. Traumatic events can be emotionally arousing; therefore emotional words are investigated to elaborate whether certain patterns of emotions are represented in narratives about the events. Cognitive words are investigated due to the idea that individuals need to make sense of the incident. Words referring to cognitive processes and emotions are used for causal explanatory frameworks and emotional integration to understand the event and to build a coherent narrative about it (Fernandez, et al., 2009; Pennebaker \& Seagal, 1999; Smyth, et al., 2001). The comparison of texts concerning different events in a single study has not yet been investigated. This study presents narratives about the above mentioned events, which are compared in terms of emotion and cognitive word use through the LIWC. Narratives were obtained in face-to-face interviews and focus groups in seven European countries. First, differences between type of events that happened in at least two countries are investigated for cultural distinctions of content dimensions in reports. Secondly, a temporal factor will be explored additional to the narratives. It is investigated if recent events contain a different amount of emotional and cognitive words than prior events. 
Method

Participants

The sample consisted of 132 people from seven European countries (Germany, United Kingdom, Spain, Sweden, Poland, Czech Republic and Turkey). Participants were recruited after having experienced one of the following types of events: residential fire, flood, terrorist attack, collapse of a building, bus accident, earthquake and/or fire in a public building. The target populations were interviewed in 32 focus groups of two to six people and in face-to-face interviews. The sample included 63 male and 66 female participants; mean age of 47.8 (SD=14.2) years. Table 2 indicates the number of participants for each of the seven European countries and types of events, as well as socio-demographics of the sample.

Table 2: Socio-demographics - Count of survivors per country, type of event, injuries, fatal casualties and sex of participants

\begin{tabular}{lll}
\hline & $\mathrm{N}$ & $\%$ \\
\hline Nation & & \\
$\quad$ Germany & 13 & 10.4 \\
United Kingdom (UK) & 10 & 7.5 \\
Spain & 11 & 11.3 \\
Sweden & 14 & 10.4 \\
Poland & 16 & 11.9 \\
Czech Republic (CZ) & 42 & 31.3 \\
Turkey & 23 & 17.2 \\
Type of event & & \\
Residential fire & 41 & 31.7 \\
Flood & 35 & 27.1 \\
Terrorist attack & 11 & 8.5 \\
Collapse of a building & 12 & 9.3 \\
Bus accident & 9 & 6.9 \\
Earthquake & 10 & 7.7 \\
Fire in public building & 11 & 8.5 \\
Injuries & & \\
Yes & 39 & 29.1 \\
No & 95 & 70.9 \\
Fatal casualties & & \\
Yes & 56 & 41.8 \\
No & 78 & 58.2 \\
Sex of participant & & \\
Male & 63 & 48.8 \\
Female & 66 & 51.2 \\
\hline
\end{tabular}


Procedure

Recruitment. Various recruitment strategies were applied across the seven European countries. Participants were recruited through firefighters, police as well as by general medical and emergency services after the incident. Via media (newspaper, internet) and public information significant events were identified. Participants were contacted personally. Some centers advertised the study in newspapers and on radio stations to raise consciousness of the study and to address potential participants. Contact addresses of the research teams were placed within those advertisements.

Inclusion criteria. Participants had to experience one of the investigated situations (residential fire, flood, earthquake, collapse of a building, terrorist attack, bus accident, fire in public building). During the event participants had to be evacuated. The situation required the attendance of medical and emergency services. The experienced event must have happened within the last ten years.

Focus groups and interviews. Focus groups and interviews were arranged at a venue of the research center or at a venue chosen by the participants for example at home. Survivors, who experienced the same type of event, were interviewed in focus groups, especially in case of domestic fires, floods and earthquakes. Focus groups were conducted to get access to a group of people with similar experiences. It was an economic and more natural setting for exploring participants' thoughts and beliefs than one-on-one interviews. Participants involved in unique type of events, like terrorist attacks, were interviewed face-to-face by one researcher. Both, focus groups and interviews were based on a semi-structured questionnaire, which assessed the participants' self-reported behavior, cognition and emotions at different stages of the situation. All interviews were conducted with at most two researchers. With the participants' permission, the interviews were audio taped. The tapes were transcribed and consistently translated into English language.

Measurement

Linguistic Inquiry and Word Count 2007 (Pennebaker, Booth, \& Francis, 2007). The transcripts were analyzed with the computerized quantitative text analysis software Linguistic Inquiry and Word Count 2007 (LIWC2007; Pennebaker, Booth, et al., 2007) introduced before. The software is able to accept written or transcribed verbal text. The LIWC 2007 contains about 80 output variables, which are written as one line of data into an output file. To give an overview, the output file includes the file name, general descriptor categories (total word count, words per sentence), standard 
linguistic dimensions (pronouns, articles, verbs), categories tapping psychological constructs (affect, cognition, biological processes), categories of personal concern (work, home, leisure activities), punctuation categories (periods, commas) and some other elements (detailed list see LIWC2007 manual; Pennebaker, Chung, et al., 2007). This research focused on the word categories tapping psychological constructs (affect, cognition). A single file or a group of files can be entered into LIWC2007 at once. For each sequentially analyzed file, a single output file is displayed. The LIWC 2007 software reads each word of a designated text file, whilst the dictionary file is searched. If a target word and the dictionary match, the word count of a certain category is increased. To give examples for the use of affect words: The sentence "I am afraid." would tap among others the following LIWC 2007 categories: "I" increases the categories pronoun and first person singular. The word "am" taps the categories verb and present tense. "Afraid" increases word count for categories anxiety and affective processes. The English dictionary was applied.

Statistical Analysis

The statistical program Stata 10.0 (StataCorp, 2007) was used. At first, differences between types of events that occurred in at least two countries were investigated for distinctions. Considering the small sample size of participants per type of event, non-parametric tests were used to calculate differences between countries. In case there were two countries per type of event, Wilcoxon rank sum test (W) was performed. In case of more than two countries per event, Kruskal-Wallis equality of populations rank test $(H)$ was performed. An additional feature for Stata 10.0 was loaded, which performs the Kruskal-Wallis equality of populations rank test and post hoc multiple comparison tests between groups (Caci, 1999). This allows the detection of overall differences as well as the location of specific group differences (Bonferroni corrected alpha; $\alpha=.001$ ). Secondly, it was investigated whether the time unit between the date of an event and its disclosure has an influence on the content of the retrospective report. Time units were assessed in days. Wilcoxon rank sum test was performed in case of two time units. For more than two units of time Kruskal-Wallis equality of populations rank test was required for analysis. The word usage rates of texts in this study were compared to the base rates of word usage of LIWC (by means and standard deviations) in order to check whether the reports contents are as emotional as texts from emotional writing studies. 
Results

Descriptives. One hundred and thirty two participants were surveyed in focus groups and interviews. Three participants had to be excluded, because of missing data. Data was assessed by seven centers in Germany, United Kingdom (UK), Spain, Sweden, Poland, Czech Republic (CZ) and Turkey. At least one type of event (residential fire, flood, terrorist attack, collapse of building, bus accident, earthquake or fire in a public building) had to be conducted by each centre. The count of participants per center and per type of event is demonstrated in table 2 and 3 . The distribution of 63 male and 66 female participants is equal. The mean age is 47.8 $(S D=14.2)$ years. Injuries over all type of events happened 39 times, fatal casualties occurred 56 times. The mean age per center ranged from 38.1 (SD=9.9) to 55.7 $(S D=13.8)$ years. A correlation was calculated to explore an influence of age on the word use of survivors. The only association between age and LIWC2007 emotion categories was found for anxiety words $(r=-.25, p=.02)$. No significant correlations were recognized between age and cognitive categories. Associations between gender and affective and cognition word categories did not reach statistical significance.

Table 3: Amount of types of events per country, socio-demographics for seven European centers

\begin{tabular}{lllllllll}
\hline & Germany & UK & Spain & Sweden & Poland & CZ & Turkey & Total \\
\hline Type of event & & & & & & & & \\
Residential fire & 6 & 2 & 5 & 2 & 10 & 7 & 9 & 41 \\
Flood & 0 & 0 & 0 & 0 & 0 & 35 & 0 & 35 \\
Terrorist attack & 3 & 8 & 0 & 0 & 0 & 0 & 0 & 11 \\
Collapse of building & 0 & 0 & 6 & 0 & 6 & 0 & 0 & 12 \\
Bus accident & 0 & 0 & 0 & 5 & 0 & 0 & 4 & 9 \\
Earthquake & 0 & 0 & 0 & 0 & 0 & 0 & 10 & 10 \\
Fire in public building & 4 & 0 & 0 & 7 & 0 & 0 & 0 & 11 \\
Total & 13 & 10 & 11 & 14 & 16 & 42 & 23 & 129 \\
Sex & & & & & & & & \\
Male & 6 & 4 & 7 & 9 & 9 & 20 & 8 & 63 \\
Female & 7 & 6 & 4 & 5 & 7 & 22 & 15 & 66 \\
Age & & & & & & & & \\
Mean & 43.07 & 55.2 & 53.72 & 39.92 & 55.75 & 50.85 & 38.17 & 47.81 \\
SD & 14.61 & 7.31 & 9.30 & 15.11 & 13.86 & 14.37 & 9.95 & 14.26 \\
\hline
\end{tabular}

Note. UK-United Kingdom, CZ -Czech Republic

1. Comparison to base rates of LIWC2007. To verify that the investigated events are equal to the narratives investigated by Pennebaker (LIWC2007 manual, p. 9; Pennebaker, Chung, et al., 2007), the means of affective and cognitive categories for the type of events were compared to the LIWC base rates. Regarding affective 
categories, collapse of a building was close to non-emotional reports. The other type of events ranged between non-emotional and emotional reported experiences. Higher scores compared to means of emotional reports were found for anxiety words in reports of bus accident and earthquake. Regarding the cognition dimension, the means for each type of event lay between non-emotional and emotional texts. Higher means were found for cognitive processes, insight and tentative words in reports about terrorist attacks. Higher amounts of inhibition words were found for the events bus accident and earthquake.

2. Explorations of differences in the expression of traumatic events between European countries. As can be seen in table 3, except for residential fire, not every event occurred in each country. Only reports about the same type of events were compared to investigate the differences of emotion and cognition word use. At first, the expression of residential fire is examined.

Residential fire. Comparing ranks for seven independent groups Kruskal-Wallis test was performed (see table 4). Differences on the LIWC 2007 affective and cognition categories were found between countries.

Table 4: Sum of ranks per country for type of event residential fire over all seven countries; KruskalWallis test statistic $(\mathrm{H})$ and $\mathrm{p}$-value

\begin{tabular}{lllllllllll}
\hline & \multicolumn{1}{l}{ Countries } & & & & & & \multicolumn{2}{l}{ Kruskal Wallis } \\
\hline & Germany & UK & Spain & Sweden & Poland & CZ & Turkey & $H$ & $\mathrm{P}$ \\
Observations & 6 & 2 & 5 & 2 & 10 & 7 & 9 & & \\
& Sum of ranks & & & & & & & & \\
Affective processes & 153.0 & 22.0 & 65.5 & 37.0 & 210.5 & 97.0 & 275.5 & 12.81 & $.04^{*}$ \\
Positive emotion & 201.0 & 41.0 & 90.0 & 67.0 & 216.0 & 127.0 & 119.0 & 13.24 & $.03^{*}$ \\
Negative emotion & 94.0 & 20.0 & 77.0 & 19.0 & 214.0 & 111.0 & 326.0 & 21.64 & $.01^{*}$ \\
Anxiety & 86.0 & 35.0 & 80.0 & 18.0 & 181.0 & 130.5 & 330.5 & 21.26 & $.01^{*}$ \\
Anger & 133.0 & 33.0 & 156.0 & 41.0 & 253.0 & 74.0 & 171.0 & 10.81 & $.09^{*}$ \\
Sadness & 78.5 & 33.0 & 126.5 & 44.5 & 184.5 & 141.0 & 253.0 & 7.22 & $.30^{*}$ \\
& & & & & & & & & \\
Cognitive processes & 201.0 & 71.0 & 31.0 & 58.0 & 167.5 & 147.0 & 185.5 & 19.25 & $.01^{*}$ \\
Insight & 102.5 & 75.0 & 67.5 & 53.0 & 223.5 & 76.0 & 263.5 & 16.26 & $.01^{*}$ \\
Cause & 100.0 & 20.5 & 85.0 & 21.0 & 286.5 & 124.5 & 223.5 & 9.99 & $.12^{*}$ \\
Discrepancy & 131.0 & 30.0 & 48.0 & 39.5 & 205.0 & 199.0 & 208.5 & 8.08 & $.23^{*}$ \\
Tentative & 153.0 & 79.0 & 87.0 & 79.0 & 295.0 & 73.0 & 95.0 & 28.16 & $.01^{*}$ \\
Certainty & 138.5 & 50.5 & 96.0 & 66.5 & 241.0 & 98.5 & 170.0 & 5.92 & $.43^{*}$ \\
Inhibition & 81.5 & 29.5 & 58.0 & 23.0 & 200.5 & 187.0 & 281.5 & 15.46 & $.01^{*}$ \\
\hline
\end{tabular}

$* p<.05$. 
Regarding affective processes, countries differed significantly in the use of affective $(H=12.81, p=.04)$, positive emotion $(H=13.24, p=.03)$, negative emotion $(H=21.64$, $p<.01)$ and anxiety words $(H=21.26, p<.01)$. Post hoc multiple comparison Wilcoxon tests were applied. No differences for the usage of affective words in general were revealed. German narratives contained significantly more positive emotion words than Turkish reports $\left(W_{\text {emp }}{ }^{1}=20.28>W_{\text {crit }}{ }^{2}=19.18, p=.0006\right)$. Turkish reports enclosed significantly more negative emotion words compared to German $\left(W_{\text {emp }}=20.56>W_{\text {crit }}=19.18, p=.0005\right)$, Spanish $\left(W_{\text {emp }}=20.82>W_{\text {crit }}=20.30, p=.0009\right)$ and Czech survivor reports $\left(W_{\text {emp }}=20.37>W_{\text {crit }}=18.34, p=.0003\right)$. Furthermore Turkish reports included a higher amount of anxiety related words than German $\left(W_{\text {emp }}=22.39>W_{\text {crit }}=19.18, p=.0001\right)$, Spanish $\left(W_{\text {emp }}=20.72>W_{\text {crit }}=20.30, p=.0009\right)$ and Polish reports ( $\left.W_{\text {emp }}=18.62>W_{\text {crit }}=16.72, p=.0003\right)$.

Regarding the cognitive categories, differences were found for cognitive processes $(H=19.25, p<.01)$, insight $(H=16.26, p<.01)$, tentative $(H=28.16, p<.01)$ and inhibition words $(H=15.46, p<.01)$. Post hoc tests revealed that cognitive process words were more frequently used by Germans than by Spanish survivors $\left(W_{\text {emp }}=27.30>W_{\text {crit }}=22.04\right.$, $p=.00008)$. Words of insight were more often used in Turkish than in Czech reports $\left(W_{e m p}=18.42>W_{c r i t}=18.34, p=.001\right)$. Regarding tentative words, three group comparisons showed no equal sum of ranks. Turkish reports contained more tentative words than British $\left(W_{e m p}=28.94>W_{c r i t}=28.45, p=.0009\right)$. And Polish reports contained more tentative words than Czech $\left(W_{e m p}=19.07>W_{\text {crit }}=17.93, p=.0006\right)$ and Turkish reports $\left(W_{\text {emp }}=18.94>W_{\text {crit }}=16.72, p=.0002\right)$. Though the category inhibition showed overall significant differences, post hoc tests revealed no differences between countries.

Each of the events terrorist attack, collapse of a building, bus accident and fire in a public building were reported in two countries and revealed the following differences (see table 5).

\footnotetext{
1 The empirical found Wilcoxon test statistic $W_{\text {emp }}$ is calculated against the critical Wilcoxon test statistic $W_{\text {crit; }}$ null hypothesis is $W_{\text {emp }}=W_{\text {crit }}$ and the probability $p$ is calculated.

2 If $W_{\text {emp }}$ is exceeding $W_{\text {crit }}$ and $p<.001$ (Bonferroni adjusted), the null hypotheses is rejected and a significant difference between two groups can be assumed.
} 
Table 5: Wilcoxon sum of ranks test (W), z-score and effect size $r$ for two group comparisons performed for the events terrorist attack, collapse of a building, bus accident and fire in a public building

\begin{tabular}{|c|c|c|c|c|c|c|c|c|c|c|c|c|}
\hline & \multicolumn{3}{|c|}{$\begin{array}{l}\text { Terrorist attack } \\
\text { Germany (3), UK (8) }\end{array}$} & \multicolumn{3}{|c|}{$\begin{array}{l}\text { Collapse of a building } \\
\text { Spain (6), Poland (6) }\end{array}$} & \multicolumn{3}{|c|}{$\begin{array}{l}\text { Bus accident } \\
\text { Sweden (5), Turkey (4) }\end{array}$} & \multicolumn{3}{|c|}{$\begin{array}{l}\text { Fire in public building } \\
\text { Germany(4), Sweden(7) }\end{array}$} \\
\hline & W & $\mathrm{z}$ & $r$ & W & $\mathrm{z}$ & $r$ & W & $\mathrm{z}$ & $r$ & W & $\mathrm{z}$ & $r$ \\
\hline Affective processes & 23.89 & $2.45^{*}$ & .73 & 39.00 & -1.76 & -.5 & 16.67 & $-2.44^{*}$ & -.81 & 27.87 & -0.47 & -.14 \\
\hline Positive emotion & 23.56 & $2.47^{*}$ & .74 & 38.73 & $-2.00^{*}$ & -.57 & 16.53 & $-2.46^{*}$ & -.82 & 28.00 & 0.94 & .28 \\
\hline Negative emotion & 23.89 & $2.45^{*}$ & .73 & 38.73 & -0.56 & -.73 & 16.67 & $-2.44^{*}$ & -.81 & 28.00 & $-1.89 *$ & -.56 \\
\hline Anxiety & 23.67 & $2.46^{*}$ & .74 & 38.32 & -1.61 & -.46 & 16.67 & $-2.44^{*}$ & -.81 & 28.00 & 0.56 & .16 \\
\hline Anger & 23.89 & $2.25^{*}$ & .67 & 39.00 & $1.92 *$ & .55 & 16.67 & -0.49 & -.15 & 27.87 & $-2.08 *$ & -.62 \\
\hline Sadness & 23.56 & $2.06^{*}$ & .62 & 38.86 & -1.60 & -.46 & 16.53 & -1.23 & -.41 & 27.87 & -0.56 & -.16 \\
\hline Cognitive processes & 24.00 & 0.00 & 0 & 39.00 & -1.21 & -.34 & 16.67 & 1.47 & .49 & 28.00 & 0.37 & .11 \\
\hline Insight & 23.89 & $-2.04 *$ & -.61 & 39.00 & 0.16 & .04 & 16.67 & -0.24 & -.08 & 28.00 & -1.13 & -.34 \\
\hline Cause & 23.89 & 1.43 & .43 & 38.86 & -0.64 & -.18 & 16.67 & -1.71 & -.57 & 28.00 & -0.37 & -.11 \\
\hline Discrepancy & 24.00 & -1.02 & -.30 & 38.73 & -0.96 & -.27 & 16.67 & 0.49 & .16 & 28.00 & 0.94 & .28 \\
\hline Tentative & 23.89 & -0.81 & -.24 & 39.00 & -1.21 & -.34 & 16.67 & $2.44^{*}$ & .81 & 27.87 & 0.00 & 0 \\
\hline Certainty & 23.89 & 1.22 & .36 & 38.86 & $-2.88^{*}$ & -.83 & 16.67 & 1.22 & .40 & 27.87 & -0.66 & .19 \\
\hline Inhibition & 23.89 & $-2.25^{*}$ & -.67 & 39.00 & 0.32 & .09 & 16.53 & $-1.96 *$ & -.65 & 27.75 & -1.70 & -.51 \\
\hline
\end{tabular}

Note. numbers in brackets are the number of reports

$* \mathrm{p}<.05$

Terrorist attack. The event terrorist attack was experienced by German and British survivors. Reports differed on each emotion related category. The British used affective words significantly more often than Germans $(r=.62-.74)$. The same direction of differing sum of ranks was found for the cognitive LIWC dimensions insight ( $z=-2.04$, $p=.04, r=-.61)$ and inhibition words $(z=-2.25, p=.02, r=-.67)$.

Collapse of a building. Experiences of the event collapse of a building were reported by Spanish und Polish survivors. The Polish used positive emotion words more often than the Spanish $(z=-2.00, p=.04, r=.-57)$. Anger words $(z=1.92, p=.05, r=.55)$ were more frequently used by Spanish survivors. The use of certainty words was significantly increased in the Polish reports $(z=-2.88, p=.00, r=-.83)$.

Bus accident. Regarding the event bus accident, Swedish and Turkish reports were compared. Results demonstrate significant differences regarding the affective categories: affective processes $(z=-2.44, p=.01, r=-.81)$, positive emotion $(z=-2.46$, $p=.01, r=-.82)$, negative emotion $(z=-2.44, p=.01, r=-.81)$ and anxiety $(z=-2.44, p=.01$, $r=-.81)$. Turkish survivors used higher amounts of these words than Swedish. Regarding cognitive categories, Swedish survivors used more tentative words $(z=2.44, p=.01$, $r=.81)$. Turkish reports contained more inhibition words $(z=-1.96, p=.04, r=.-65)$. 
Fire in a public building. German and Swedish survivors experienced this type of event. The Swedish reported significantly more negative emotion ( $z=-1.89, p=.05, r=-$ .56) and anger words ( $z=-2.08, p=.03, r=-.62$ ). No differences between the sum of ranks for the cognition related word categories were found.

All in all, moderate to large effect sizes for the significant comparisons can be recognized, ranging from $r=.55$ to .83 (Rosnow \& Rosenthal, 2009).

3. Temporal differences in retrospective reports of the same type of event. As presented previously, survivors of residential fires were interviewed across all national centres. The time elapsed between the event and conduction of focus groups and interviews differed. Some experienced fires happened just a few days before the focus group or interview, others several years before. A sensible question is whether the difference in time is reflected in retrospective reports of the event. Is an event that dates back several years reported the same way as one that dates back only a few days or weeks, especially regarding affective and cognitive word use? For the nations of Czech Republic, Poland, Turkey and Germany, several reports of the event residential fire were available (see table 6). In the following, "time unit" describes the same amount of days elapsed between the event and interview. The reports of Spanish (five reports after 379 days) and Swedish participants (two reports after 449 days) could not be calculated, because all survivors reported at the same time unit and no comparison is possible. In the British sample two time units (1962; 2871 ) with only one survivor each reported about residential fire. No differences were found on the LIWC dimensions.

Table 6: Comparisons for the event residential fire in four countries after different units of time between the event and the focus groups: Wilcoxon sum of ranks test (W), z-score, p-value and effect size $r$ for two group comparisons; Kruskal Wallis equality of populations rank test $(\mathrm{H})$ and $\mathrm{p}$ value for three group comparison tests

\begin{tabular}{|c|c|c|c|c|c|c|c|c|c|c|}
\hline & \multicolumn{10}{|c|}{ Residential fire } \\
\hline \multirow{5}{*}{$\begin{array}{l}\text { Days between } \\
\text { event and focus } \\
\text { group/interview } \\
\text { (number of reports) }\end{array}$} & \multicolumn{4}{|c|}{ Czech Republic } & \multicolumn{2}{|c|}{ Germany } & \multicolumn{2}{|l|}{ Poland } & \multicolumn{2}{|c|}{ Turkey } \\
\hline & \multicolumn{4}{|c|}{$662(4)$} & \multicolumn{2}{|l|}{$28(2)$} & \multicolumn{2}{|l|}{$180(3)$} & \multicolumn{2}{|c|}{$106(5)$} \\
\hline & \multirow{2}{*}{\multicolumn{4}{|c|}{$2959(3)$}} & \multicolumn{2}{|l|}{$58(2)$} & \multicolumn{2}{|l|}{$201(2)$} & \multicolumn{2}{|c|}{$130(2)$} \\
\hline & & & & & \multicolumn{2}{|c|}{$120(2)$} & \multicolumn{2}{|l|}{$306(5)$} & \multicolumn{2}{|c|}{$221(2)$} \\
\hline & W & z & $\mathrm{p}$ & $r$ & $\mathrm{H}$ & $\mathrm{p}$ & $\mathrm{H}$ & $\mathrm{p}$ & $\mathrm{H}$ & $\mathrm{p}$ \\
\hline Affective processes & 8.00 & -1.06 & .28 & -.40 & 3.42 & .18 & 1.37 & .50 & 0.36 & .83 \\
\hline Positive emotion & 8.00 & 0.00 & 1.00 & 0 & 0.85 & .65 & 1.57 & .45 & 3.24 & .19 \\
\hline Negative emotion & 8.00 & -1.41 & .15 & -.53 & 4.57 & .10 & 0.01 & .99 & 0.77 & .67 \\
\hline Anxiety & 8.00 & -1.06 & .28 & -.40 & 4.57 & .10 & 2.72 & .25 & 3.33 & .18 \\
\hline Anger & 7.43 & 0.00 & 1.00 & 0 & 4.57 & .10 & 3.41 & .18 & 0.77 & .67 \\
\hline Sadness & 7.86 & -0.53 & .59 & -.20 & 1.14 & .56 & 0.89 & .64 & 0.34 & .84 \\
\hline
\end{tabular}




\begin{tabular}{clllllllllll}
\hline Cognitive processes & 8.00 & -1.06 & .28 & -.40 & 3.42 & .18 & 2.45 & .29 & 3.77 & .15 \\
Insight & 8.00 & -2.12 & $.03^{*}$ & -.80 & 3.71 & .15 & 1.14 & .56 & 0.81 & .66 \\
Cause & 8.00 & 1.06 & .28 & .40 & 2.00 & .36 & 0.72 & .69 & 2.97 & .22 & .11 \\
Discrepancy & 8.00 & 0.70 & .47 & .26 & 0.00 & 1.00 & 1.45 & .48 & 4.29 & .11 \\
Tentative & 8.00 & .35 & .72 & .13 & 2.00 & .36 & 4.72 & .09 & 3.33 & .18 & .47 \\
Certainty & 8.00 & -2.12 & $.03^{*}$ & -.80 & 2.00 & .36 & 0.01 & .99 & 1.94 & .47 \\
Inhibition & 8.00 & -1.76 & .07 & -.66 & 2.00 & .36 & 5.28 & .07 & 3.97 & .13 \\
\hline
\end{tabular}

$* \mathrm{p}<.05$.

Residential fire in Czech Republic was experienced and reported by seven survivors interviewed in two focus groups after two time units. Three survivors reported after 2959 days (almost eight years) and four after 602 days. A Wilcoxon rank sum test was performed. No differences regarding affective LIWC categories were recognized. Hence, significant differences appeared in two cognition categories. Words expressing insight $(z=-2.12, p=.03, r=-.80)$ and certainty $(z=-2.12, p=.03, r=-.80)$ were more frequently used by the survivors who reported about a fire which happened almost eight years ago.

Kruskal-Wallis test showed no differences in the affective and cognitive categories in Polish, Turkish and German reports.

\section{Discussion}

The current study is one of the first studies comparing the use of affective and cognitive words in narratives about traumatic situations across nations. The study is genuinely explorative and was conducted to elicit research questions concerning the cross-cultural use of the LIWC categories. The base rates of word usage from LIWC studies were compared to the investigated narratives about traumatic events. As demonstrated, narratives scored higher than the texts from the control condition and contained equal amounts of affective and cognitive words as texts from LIWC studies with emotional and traumatic conditions (LIWC2007 Manual; Pennebaker, Chung, et al., 2007). Accordingly, the narratives used here can be considered as charged with emotions. The reports are considered useful material for this investigation.

With regard to the linguistic characteristics of the narratives, the following can be observed: The reports about residential fire, terroristic attack and bus accident contained words of the LIWC categories affective processes, positive emotion, negative emotion and anxiety. The events collapse of a building and fire in a public building additionally enclosed anger words. Concerning the cognitive categories, insight and inhibition words occurred more often in narratives about residential fire, 
terrorist attacks and bus accidents. Collapse of a building was narrated with more words of certainty. Fire in a public building contained no significant differences in the use of words regarding cognitive processes. To sum up, traumatic situations were reported with a greater amount of negative emotion words, which is in line with and confirms prior research results (Fernandez, et al., 2009; Gortner \& Pennebaker, 2003).

A unique feature of this study is the exploration of verbal expression for different types of events. Some types of events occurred in only two countries, but differences were recognized as well. Besides some differences regarding the content LIWC categories between participating survivors, most of the word usage was similar between the reports collected from different nations. The reports of Turkish survivors stick out with respect to the topic of residential fire. The narratives enclosed higher amounts of negative emotion and anxiety words than texts from German, Spanish and Czech survivors. Regarding the event bus accident, Turkish reports displayed more affective processes, positive and negative emotion as well as anxiety words than Swedish narratives. Our findings suggest that the Turkish way to express emotional content is more verbally outspoken in comparison to the other investigated countries. Turkish reports stood out in comparison to rather unspecific differences of the other countries' narratives as well. Turkish reports contained more words in general and were longest compared to the other countries' narratives.

Unsurprisingly, negative emotion words were mainly used across all narratives. Even though positive emotion words could be found in reports of residential fire by Germans, collapse of a building by Polish and bus accident by Turkish survivors. The use of positive emotion words in the context of severe events seems at first counterintuitive. Considering that the LIWC software counts single words, it is possible that phrases expressing luck or being glad count for the positive emotion dimensions. The appraisal of surviving a certain event may also lead to positive expressions in the narration. Expressing positive emotions in narrations of traumatic events seems also commonplace and is considered to be a coping strategy (Han, et al., 2007). Therefore, significant differences regarding positive emotion words are coherent even in traumatic event reports. In contrast, the expression of words relating to cognitive mechanisms in different countries is rather ambiguous and heterogeneous. To interpret the findings properly more validating studies are needed. Further research including bigger sample sizes is recommended to accurately interpret the findings for cognition word usage.

Thus, cultural differences on the LIWC categories were found, but can only be a hint for prospective research on this subject. Beneath considerable cultural differences, the findings may also be due to situational factors of the event (emotionally arousing 
vs. capable, etc.), the impact of the event, the narrating style (emotional vs. nonexpressive) and length, as well as the temporal gap between the event and the interview (Tuval-Mashiach, et al., 2004).

The investigation of a temporal factor, in terms of days elapsed between the event and the interview about it, was performed on the event residential fire. The time units ranged from 28 day to 2959 days between the traumatic event (fire) and the participation in focus groups. According to the collective coping theory (Pennebaker \& Harber, 1993), the rate of affective word use should be heightened shortly after the event. Survivors should still be emotionally involved and express their feelings verbally with emotion related words. After an estimated four to six weeks, the event should be emotionally processed and a decrease of emotion word usage should be noted. Our results showed no significant differences in the use of affective words, whether the time unit was 28,120 or 306 days, which was against the expectations. In contrast to the model of Pennebaker \& Harber (1993), who claimed increased thoughts or cognitions, no differences were found three to ten months after the event regarding the cognitive categories. Survivors, who reported about the fire after eight years, used a higher amount of insight and certainty words. Supposedly, the delayed reporting about this event required more cognitive processing, which is a sign of sense making, reasoning about the experience and building a coherent story (Cohn, et al., 2004; Gortner \& Pennebaker, 2003). An event which happened longer ago needs to be mentally reconstructed and requires more cognition related words. Recalling the event after several years affords increased cognitive resources, which are also expressed verbally.

Advantages of this research

This study combined some unique features of research. At first, participants of seven European countries have been recruited. Second, information about seven different events has been conducted. Third, cultural and temporal differences in narratives have been explored. These features altogether have not been accounted for until now. A new issue considered in this research is the investigation of communication in focus groups. Focus groups are a common technique in organizations. Here, they were implemented because of practical and economical considerations. A focus group consists of two to six people, who experienced the same event. Therefore the costs of leading six face-to-face interviews are saved. Though interviews have been part of earlier investigation, the method of focus groups in this field of research is innovative. Participants enjoyed the experience of coming together and exchanging experiences. Analyzing focus groups and interviews with a quantitative 
text analysis software like LIWC2007 is a rare and special way to explore differences in the expression of traumatic events.

In conclusion, we found differences in the expressed word basis between countries for the investigated type of event residential fire and regarding a temporal factor. We focused on the expression of affective and cognitive words, which are relevant when it comes to positive health changes and coping with traumatic events, like breast cancer (Alpers, et al., 2005; Pennebaker, et al., 2003) or tragic accidents (Gortner \& Pennebaker, 2003). Individuals who talk about traumatic events in their lives gain greater health benefits when using positive emotion words, a moderate use of negative emotion words and an increased amount of words regarding cognitive processes (Pennebaker \& Francis, 1996). The health issues have not been investigated here, but are suggested for further research.

Limitations of the study

First to be mentioned are the small sample sizes per country and per type of event, which were due to the type of crisis situations included and the in-depth approach of qualitative interviews. A common criticism in leading face-to-face interviews and focus groups is that participants consider their stories not interesting or unimportant for research. Hence, individuals are likely to conceal information while they narrate. Secondly, social desirable statements and the cultural context must be taken into consideration. To recall and disclose behaviors and feelings after being in threatening situations can be intimidating and unpleasant. Talking about very personal feelings is not common sense in some cultures (for example in Asia) and can be socially sanctioned. Eventually, participants didn't disclose their real feelings and answered in socially desirable ways. More shortcomings of focus groups can be decreased expressivity of participants due to personal characteristics (extraversion vs. submission) and limited time of the focus group. Transcripts revealed participants with more or less fractions of talk. A further consideration is that some of the memories of participants have been synchronized due to the group approach, so a homogenous story is told instead of individual experiences (as a need for coherent stories). A further shortcoming is that the impact of each event has not been considered, because of the small sample sizes.

All interviews and focus groups were transcribed in original language and translated into English. Due to the translation process from native language into English, a loss of information can be considered. Therefore, all narratives should have been analyzed in their native language, but LIWC dictionaries were not available for the following languages: Swedish, Polish and Czech. For consistent evaluation translated English 
texts were used. Therefore the linguistic dimensions of the LIWC2007 had to be neglected. Special characteristics of each language risk remaining unnoticed in the translation and differences can occur. The focus was rather on the content-related LIWC dimensions, which offer insight into crucial emotional and cognitive processes of the participants.

Implications for further research

Differences between survivors of European countries narrating about different types of events were found. Investigating several type of events is an ambitious aim. It might be therefore considered to explore just one type of event, like WTC attacks on September $11^{\text {th }} 2001$ (Fernandez, et al., 2009). These events are unique and traumatic. Therefore research should focus on more common events like residential fires, earthquakes or floods. Additional focus should be on the impact of those events on survivors and the eventual correlative verbal expression of those experiences, i.e. higher emotional word usage after highly threatening events.

In order to explore cultural differences regarding linguistic dimensions the investigation of reports in the original language is recommended for further research. Moreover, this study was rather exploratory and needs to be validated in studies with higher rates of participants per type of event. Further research on cultural, linguistic and content-related differences within European countries is needed to verify and complement our results. To investigate what bothers individuals emotionally and cognitively after such a traumatic situation might lead to implications for coping or communication about these situations. Hence, this can result in practical communication strategies between survivors and medical and emergency services after those events.

In conclusion, this study was able to present some preliminary analyses of cultural diversity in the expression of various traumatic events in survivors from seven European countries, and to explore a temporal factor related to the way in which events are reported retrospectively.

\section{Acknowledgements}

This paper was written on behalf of the BeSeCu group by Simone Freitag, Anna Grimm and Silke Schmidt. Project BeSeCu (contract 218324) is funded under the European Union Framework 7 Security initiative. The authors acknowledge the co-operation of their project partners: Ernst-Moritz-Arndt University Greifswald, Department of Health and Prevention, Germany (project co-ordinator Prof. Dr. Silke Schmidt); University of 
Greenwich, FSEG, UK; Institute of Public Security of Catalunya, Spain; Hamburg Fire and Emergency Service Academy, Germany; MTO Psykologi, Sweden; Prague Psychiatric Centre, Czech Republic; Main School of Fire Service, Poland; Hamburg Fire and Emergency Service Academy, Germany and Association of Emergency Ambulance Physicians, Turkey; in undertaking this work and in allowing the project findings to be published.

\section{References}

Alpers, G. W., Winzelberg, A. J., Classen, C., Roberts, H., Dev, P., Koopman, C., et al. (2005). Evaluation of computerized text analysis in an Internet breast cancer support group. Computers in Human Behavior, 21 (2), 361-376.

Alvarez-Conrad, J., Zoellner, L. A., \& Foa, E. B. (2001). Linguistic predictors of trauma pathology and physical health. Applied Cognitive Psychology, 15(7), S159-170.

Bantum, E. O., \& Owen, J. E. (2009). Evaluating the Validity of Computerized Content Analysis Programs for Identification of Emotional Expression in Cancer Narratives. Psychological Assessment, 21 (1), 79-88.

Caci, H. M. (1999). KWALLIS2, from http://ideas.repec.org/c/boc/bocode/s379201.html

Carroll, B., Morbey, H., Balogh, R., \& Araoz, G. (2009). Flooded homes, broken bonds, the meaning of home, psychological processes and their impact on psychological health in a disaster. Health \& Place, 15(2), 540-547.

Chung, C. K., \& Pennebaker, J. W. (2007). The Psychological Function of Function Words. In K. Fiedler (Ed.), Social Communication (pp. 343-359). New York: Psychology Press.

Cohn, M. A., Mehl, M. R., \& Pennebaker, J. W. (2004). Linguistic markers of psychological change surrounding September 11, 2001. Psychological Science, 15(10), 687-693.

Fernandez, I., Paez, D., \& Pennebaker, J. W. (2009). Comparison of expressive writing after the terrorist attacks of September 11 [sup]th[/sup] and March 11 [sup]th[/sup]. International Journal of Clinical and Health Psychology, 9(1), 89-103.

Galea, S., Ahern, J., Resnick, H., Kilpatrick, D., Bucuvalas, M., Gold, J., et al. (2002). Psychological sequelae of the September 11 terrorist attacks in New York City. The New England Journal of Medicine, 346(13), 982-987. 
Gill, A. J., French, R. M., Gergle, D., \& Oberlander, J. (2008). The Language of Emotion in Short Blog Texts Proceedings of CSCW 2008 (pp. 299-302). New York ACM Press. .

Gortner, E.-M., \& Pennebaker, J. W. (2003). The Archival Anatomy of a Disaster: Media Coverage and Community-wide Health Effects of the Texas A\&M Bonfire Tragedy. Journal of Social \& Clinical Psychology, 22 (5), 580.

Groom, C. J., \& Pennebaker, J. W. (2002). Words. Journal of Research in Personality, $36(6), 615-621$.

Han, J. Y., Hawkins, R., Pingree, S., McTavish, F., Gustafson, D., \& Shaw, B. (2007, 20072007 Annual Meeting). Exploring the Role of Expressing Positive Emotions Within Online Support Groups on Women With Breast Cancer. Paper presented at the Conference Papers -International Communication Association.

Keane, A., Pickett, M., Jepson, C., McCorkle, R., \& Lowery, B. J. (1994). Psychological distress in survivors of residential fires. Social Science \& Medicine, 38(8), 1055-1060.

Kessler, R. C., Sonnega, A., Bromet, E., Hughes, M., \& Nelson, C. B. (1995). Posttraumatic stress disorder in the National Comorbidity Survey. Archives of General Psychiatry, 52, 1048-1060.

Livanou, M., Kasvikis, Y., Basoglu, M., Mytskidou, P., Sotiropoulou, V., Spanea, E., et al. (2005). Earthquake-related psychological distress and associated factors 4 years after the Parnitha earthquake in Greece. European Psychiatry, 20(2), 137-144.

Marsella, A. J., Johnson, J. L., Watson, P., \& Gryczynski, J. (Eds.). (2008). Ethnocultural Perspectives on Disaster and Trauma: Foundations, Issues, and Applications. New York: Springer Science+Business Media.

Miguel-Tobal, J. J., Cano-Vindel, A., Gonzalez-Ordi, H., Iruarrizaga, I., Rudenstine, S., Vlahov, D., et al. (2006). PTSD and depression after the Madrid March 11 train bombings. Journal of Traumatic Stress, 19(1), 69-80.

Pasupathi, M. (2007). Telling and the remembered self: Linguistic differences in memories for previously disclosed and previously undisclosed events. Memory, 15(3), 258-270.

Pennebaker, J. W., \& Beall, S. K. (1986). Confronting a Traumatic Event: Toward an Understanding of Inhibition and Disease. Journal of Abnormal Psychology, 95(3), 274-281. 
Pennebaker, J. W., Booth, R. J., \& Francis, M. E. (2007). Linguistic Inquiry and Word Count: LIWC [Computer software]. Austin, TX: LIWC.net.

Pennebaker, J. W., Chung, C. K., Ireland, M., Gonzales, A., \& Booth, R. J. (2007). The development and psychometric properties of LIWC2007. Austin, TX: LIWC.net.

Pennebaker, J. W., \& Francis, M. E. (1996). Cognitive, emotional, and language processes in disclosure. Cognition and Emotion, 10(6), 601-626.

Pennebaker, J. W., \& Harber, K. D. (1993). A social stage model of collective coping: The Loma Prieta earthquake and the Persian Gulf War. Journal of Social Issues, 49(4), 125-145.

Pennebaker, J. W., Mehl, M. R., \& Niederhoffer, K. G. (2003). Psychological Aspects of Natural Language Use: OurWords, Our Selves. Annual Review Psychology, 54, 547-577.

Pennebaker, J. W., \& Seagal, J. D. (1999). Forming a story: The health benefits of narrative. Journal of Clinical Psychology, 55(10), 1243-1254.

Rosnow, R. L., \& Rosenthal, R. (2009). Effect sizes: Why, when, and how to use them. Zeitschrift f $\tilde{A} 1 / 4$ r Psychologie/Journal of Psychology, $217(1), 6-14$.

Rullkoetter, N., Bullig, R., Driessen, M., Beblo, T., Mensebach, C., \& Wingenfeld, K. (2009). Autobiographical memory and language use: linguistic analyses of critical life event narratives in a non-clinical population. Applied Cognitive Psychology, 23 (2), 278-287.

Schlenger, W. E., Caddell, J. M., Ebert, L., Jordan, B. K., Rourke, K. M., Wilson, D., et al. (2002). Psychological reactions to terrorist attacks: Findings from the National Study of Americans' Reactions to September 11. JAMA: Journal of the American Medical Association, 288(5), 581-588.

Smyth, J., Hockemeyer, J., \& Tulloch, H. (2008). Expressive writing and post-traumatic stress disorder: Effects on trauma symptoms, mood states, and cortisol reactivity. British Journal of Health Psychology, 13(1), 85-93.

Smyth, J., True, N., \& Souto, J. (2001). Effects of writing about traumatic experiences: The necessity for narrative structuring. Journal of Social and Clinical Psychology, 20 (2), 161172.

StataCorp (2007). Stata Statistical Software: Release 10. TX: StataCorp LP. 
Tuval-Mashiach, R., Freedman, S., Bargai, N., Boker, R., Hadar, H., \& Shalev, A. Y. (2004). Coping with Trauma:Narrative and Cognitive Perspectives. Psychiatry, 67(3), 280-293.

Ulrich, P. M., \& Lutgendorf, S. K. (2002). Journaling About Stressful Events: Effects of Cognitive Processing and Emotional Expression. Annals of Behavioral Medicine, 24 (3), 244.

Yeomans, P. D., Forman, E. M., Eshun, S., \& Gurung, R. A. R. (2009). Cultural factors in traumatic stress Culture and mental health: Sociocultural influences, theory, and practice. (pp. 221-244): Wiley-Blackwell.

About the authors:

Simone Freitag is a psychologist and PhD student. She works as a scientific assistant at the Department Health and Prevention at the Ernst-Moritz-Arndt University of Greifswald. One of the main research interests is the application of Linguistic Inquiry and Word Count (LIWC) to different populations and issues (e.g. word usage in traumatic situations, in biography narration of aged people, etc.).

Address for correspondance: Simone Freitag, Robert-Blum-Str. 13, 17487 Greifswald, Germany

E-mail: simone.freitag@uni-greifswald.de

Anna Grimm is a psychologist and PhD student at the Department Health and Prevention at the Ernst-Moritz-Arndt University of Greifswald. Her main research interests are the behavior and emotions of people surviving different types of crisis situations.

Silke Schmidt is professor and head of the Department Health and Prevention at the Ernst-Moritz-Arndt University of Greifswald. One of the areas of research is cross cultural assessment of mental and physical health as well as quality of life. A second focus is on psychological prevention. 